\title{
Mechanical Characterization and Measurement of the Damage of Pericopsis elata (Assamela)
}

\author{
Ulrich Gael Azeufack ${ }^{1,2,3}$, Bienvenu Kenmeugne ${ }^{4}$, Emmanuel Foadieng1, Martial Fouotsa', \\ Pierre Kisito Talla ${ }^{*}$, M. Fogue ${ }^{2}$
}

\author{
${ }^{1}$ Research Unit of Mechanics and Physical Systems Modeling (UR2MPS), Department of Physics, University of Dschang, \\ Dschang, Cameroon \\ ${ }^{2}$ Research Unit of Engineering of Industrial Systems and Environment (URISIE), UIT-FV Bandjoun, University of Dschang, \\ Dschang, Cameroon \\ ${ }^{3}$ Innovation Research Center Entrepreneurship (PRIE), Institut Universitaire de la Côte, Douala, Cameroon \\ ${ }^{4}$ Laboratoire d’Engineering Civil et Mécanique (LECM), Ecole Nationale Supérieure Polytechnique de Yaoundé, Yaoundé, \\ Cameroon \\ Email: *tpierrekisito@yahoo.com
}

How to cite this paper: Azeufack, U.G., Kenmeugne, B., Foadieng, E., Fouotsa, M., Talla, P.K. and Fogue, M. (2019) Mechanical Characterization and Measurement of the Damage of Pericopsis elata (Assamela). World Journal of Engineering and Technology, 7, 256-269.

https://doi.org/10.4236/wjet.2019.72017

Received: November 24, 2018

Accepted: March 11, 2019

Published: March 14, 2019

Copyright $\odot 2019$ by author(s) and Scientific Research Publishing Inc. This work is licensed under the Creative Commons Attribution International License (CC BY 4.0).

http://creativecommons.org/licenses/by/4.0/

\section{(c) (i) Open Access}

\begin{abstract}
The prediction of the mechanical properties of wood and the evolution of its damage has been essential for its application in many fields such as bridges and houses construction, racks of trucks and so on. In more valorization of biomaterials following the example material wood arouses for a few years a private interest on behalf of the populations. The experimental characterization makes it possible to consider the mechanical properties local of Pericopsis elata (Assamela) according to various parameters (the wood turpentine, the orientation of wood fibers, water the content, the type of test ...). From the results, we evaluate the mechanical characteristics of Pericopsis elata (Assamela) according to the three directions of Orthotropy. Then from the tests of load-discharge we measured the evolution of the damage using the variation of the Young modulus, which enabled us to note the reduction in the modulus of elasticity because of the damage following the three directions. Finally we noted a progressive and irreversible degradation of mechanical properties induced by the development of the microscopic cracks within material.
\end{abstract}

\section{Keywords}

Wood, Mechanical Properties, Modulus of Elasticity, Damage, Orthotropic, Cycles Loading, Unloading

\section{Introduction}

Germination, the growth and the coalescence of the cavities are the mechanism 
concerned for the rupture within the material wood, since 1958 by Kachanov which describes the evolution of the deterioration of a material and introduced the concept of variable of damage. Damage anisotropy refers to the phenomenon that a material is vulnerable to damage in some directions but resistant to damage in some other, due to certain texture patterns or certain external loads. Several authors [1] [2] [3] modeled damage isotropy, and several others [4] [5] [6] took damage anisotropy into account. Then the concept of effective constraint which allows the measurement of the damage by the variation of the characteristics of elasticity has been introduced [7] [8]. Many work then largely contributed to the comprehension of the phenomenon and the mechanical damage in general. Among them, the authors such as [9]-[14] particularly treat anisotropy of the damages caused on the wood which is an orthotropic material. The three directions of Orthotropy of wood generate a symmetry which is found in the majority of its mechanical properties. [15] [16] [17] [18] proposed stress-strain models of confined concrete including an unloading and reloading paths. From this Orthotropy, the mechanical characterization of wood is based on the determination of three moduli of elasticity, three shear moduli and six Poisson's ratios. The mathematical expression of the elastic behavior of wood can be reduced to a symmetrical matrix with nine elastic constants. Hooke's law can be generalized to the axes $L, R$ and $T$ and the elastic compliance matrix is given by [19] [20] [21]:

$$
\left[\begin{array}{c}
\varepsilon_{L} \\
\varepsilon_{R} \\
\varepsilon_{T} \\
\gamma_{R T} \\
\gamma_{L T} \\
\gamma_{L R}
\end{array}\right]=\left[\begin{array}{cccccc}
\frac{1}{E_{L}} & -\frac{v_{R L}}{E_{R}} & -\frac{v_{T L}}{E_{T}} & 0 & 0 & 0 \\
-\frac{v_{L R}}{E_{L}} & \frac{1}{E_{R}} & -\frac{v_{T R}}{E_{T}} & 0 & 0 & 0 \\
-\frac{v_{L T}}{E_{L}} & -\frac{v_{R T}}{E_{R}} & \frac{1}{E_{T}} & 0 & 0 & 0 \\
0 & 0 & 0 & \frac{1}{G_{R T}} & 0 & 0 \\
0 & 0 & 0 & 0 & \frac{1}{G_{L T}} & 0 \\
0 & 0 & 0 & 0 & 0 & \frac{1}{G_{L R}}
\end{array}\right]\left[\begin{array}{c}
\sigma_{L} \\
\sigma_{R} \\
\sigma_{T} \\
\tau_{R T} \\
\tau_{L R} \\
\tau_{L R}
\end{array}\right]
$$

$\varepsilon_{L}, \varepsilon_{R}, \varepsilon_{T}$ : Deformation according to 3 directions;

$\gamma_{R T}, \gamma_{L T}, \gamma_{L R}$ : Shear strains according to 3 plans of shearing;

$E_{L}, E_{R}, E_{T}$ : Moduli of elasticity according to 3 directions;

$G_{R T}, G_{L T}, G_{L R}$ : Shear moduli according to 3 plans;

$\sigma_{L}, \sigma_{R}, \sigma_{T}$ : Normal stress in 3 directions;

$v_{L R}, v_{R L}, v_{T L}, v_{L T}, v_{R T}, v_{T R}:$ Poisson's ratios;

$\tau_{R T}, \tau_{L T}, \tau_{L R}:$ Shear stress in 3 directions.

We can therefore say that 9 independent linear elastic coefficients characterize a continuous, homogeneous and orthotropic body in an orthotropic base.

$$
\frac{v_{L R}}{E_{L}}=\frac{v_{R L}}{E_{R}} ; \frac{v_{L T}}{E_{L}}=\frac{v_{T L}}{E_{T}} ; \frac{v_{R T}}{E_{R}}=\frac{v_{T R}}{E_{T}}
$$


The elastic properties of wood are sensitive to the variation of its physical state. Among the physical influences, the main parameters are: density, the rate moisture and the temperature. On the practical level, for fluctuations in a range of moisture content between 6 and the corrections of the adopted moduli of elasticity and shear are the following:

$$
\begin{array}{ll}
E_{L}^{H}=E_{L}^{12}[1-0.015 H-12] & G_{R T}=G_{R T}^{12}[1-0.030(H-12)] \\
E_{R}^{H}=E_{R}^{12}[1-0.030 H-12] & G_{T L}=G_{T L}^{12}[1-0.030(H-12)] \\
E_{T}^{H}=E_{T}^{12}[1-0.030 H-12] & G_{L R}=G_{L R}^{12}[1-0.030(H-12)]
\end{array}
$$

The relationships between the longitudinal modulus of elasticity and the shear modulus are given by [22] [23] [24]:

$$
G_{L R}=\frac{E_{L}}{15} ; \quad G_{L T}=\frac{E_{L}}{17} ; G_{R T}=\frac{E_{L}}{153}
$$

The relationship between the modulus of elasticity in the longitudinal direction and the other moduli of elasticity in the other two directions is given by [22] [23]:

$$
E_{R}=\frac{E_{L}}{13} ; \quad E_{T}=\frac{E_{L}}{21}
$$

\section{Orthotropy of Wood Material}

Regarding the Orthotropy of the wood, it recognizes different physical and mechanical characteristics in each of its directions. The three main directions in wood are: the longitudinal direction $(L)$, the radial direction $(R)$ and the tangential direction $(T)$ in Figure 1. In this reference, the Orthotropy generates three planes of symmetry $(L T, R S, S L)$. This Orthotropy has a direct impact on the physico-mechanical properties of Wood.

\section{Material and Methods}

\subsection{Water Content}

The evolution of the humility rate $(H)$ in wood shows that starting from the anhydrous state, the water impregnates the ligneous material until reaching a limit which is around the $30 \%$ water content of the Wood. This limit is called fiber saturation point (PSF). According to standard NF B 51-004 [25], the value of the moisture content of wood is defined by the ratio of the mass of water it contains $\left(m_{H}-m_{0}\right)$ to the mass $\left(m_{0}\right)$ of anhydrous wood where $m_{H}$ is the mass of wet wood.

$$
H=\frac{m_{H}-m_{0}}{m_{0}} \times 100
$$

$H$ : water content;

$m_{H}:$ mass wood with moisture $H$;

$m_{0}:$ mass wood in an anhydrous state;

$m_{H}-m_{0}:$ mass water contained in wood. 


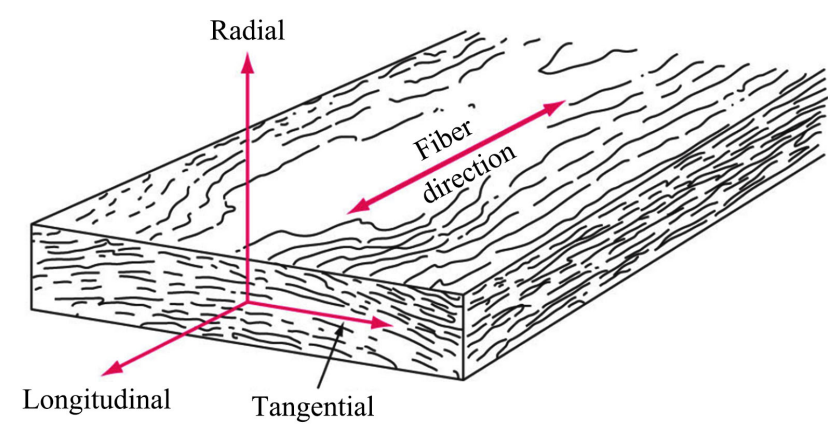

Figure 1. Mains direction of Orthotropy of the wood material.

\subsection{Evolution of the Damage}

These tests will be carried out with an aim of studying the evolution of the damage in the material wood. They make it possible to determine qualitatively if a material is brittle or ductile, rigid or flexible. Also to quantify the mechanical properties such as the modulus of elasticity, maximum resistance, elongation at fracture in traction. The tests will be carried out at a constant speed.

With regard to material wood, when the yield stress is exceeded, the cellular walls undergo a buckling what damages material. This has as a consequence the reduction in the modulus of elasticity in load-discharge. Plasticity is only apparent and is accompanied by damage. The rupture in compression of material presents a ductile characteristic; it occurs a phenomenon of buckling of the fibers [22] [26].

\subsection{Description of the Machine}

A modern compression traction machine has an adjustable electric drive to perform simple or cyclic controlled speed tests.

The figure presents the kinematic diagram of the testing machine of compression which we used. The engine is started by power supply. Oil circulates from the oil vat through the pipes and pressurly arrives in the cylinder (4). This pressure involves the displacement of the piston (3) which, once in contact with the test-tube, gradually compresses it (adjustment of the race by the operator) until the rupture of the test-tube. The pressure and the shortening are simultaneously recorded.

Figure 2 shows the kinematic diagram of the compression testing machine we used.

A frame consisting of four interdependent amounts two by two through a crosspiece.

1) A base plate in UPN on which rests the four uprights.

2) Two longitudinal members (each fixed to two uprights) adjustable in the vertical compared to the uprights, thanks to the dismountable screw-nut assembly. On these rails is fixed the lower jaw.

3) A piston whose linear displacement of the rod causes the extension or the compression of the sample. 




Figure 2. Kinematic diagram of the testing machine tension/compression.

4) A cylinder body, in which houses the control piston.

5) A driving pipe for the repression of the oil.

6) Another piping allowing the aspiration of the oil.

7) A manometer to evaluate the intensity of the effort applied.

8) An electric motor powered by a $D_{C}$ socket, a box containing oil, filter elements and oil pumping.

\subsection{Description of the Compression Test Specimen}

The compression sample have dimensions $30 \times 30 \times 90 \mathrm{~mm}$ [22] (Figure 3).

The elastic constants are given by the following relationships:

$$
E_{L}=\frac{\sigma_{L}}{\varepsilon_{L}} ; v_{L R}=\frac{\varepsilon_{R}}{\varepsilon_{L}} ; v_{L T}=\frac{\varepsilon_{T}}{\varepsilon_{L}}
$$

\section{Results and Discussed}

Figure 4 shows the common shape of the experimental stress-strain curves similar to that seen in the literature. Thanks to the linear regression, we deduce the slope of the linear part which gives the desired Young's modulus. This approach to the choice of the slope for the determination of the Young's modulus obeys Hooke's law, with correlation factors greater or equal to 0.99 , allowing us to conclude that the tests were well done. The desired Young's modulus is the average of 15 Young's moduli on 15 specimens in the radial, longitudinal and tan- 
gential directions. The curves in Figure 4 give the experimental results of the simple compression test on specimens cut in the longitudinal, radial and tangential directions and its mechanical response to simple compression loading.

All the tests carried out, the curves obtained have almost the same pace according to the different directions. The first slope of the curve of the experimental points gives the Young's modulus. The Young's modulus of Pericopsis elata is the average of the Young's moduli of fifteen specimens studied in each direction of Orthotropy. The tables show some average results obtained from these tests. Tables 1-3 show the values obtained from these curves and also the average values according to the different directions.
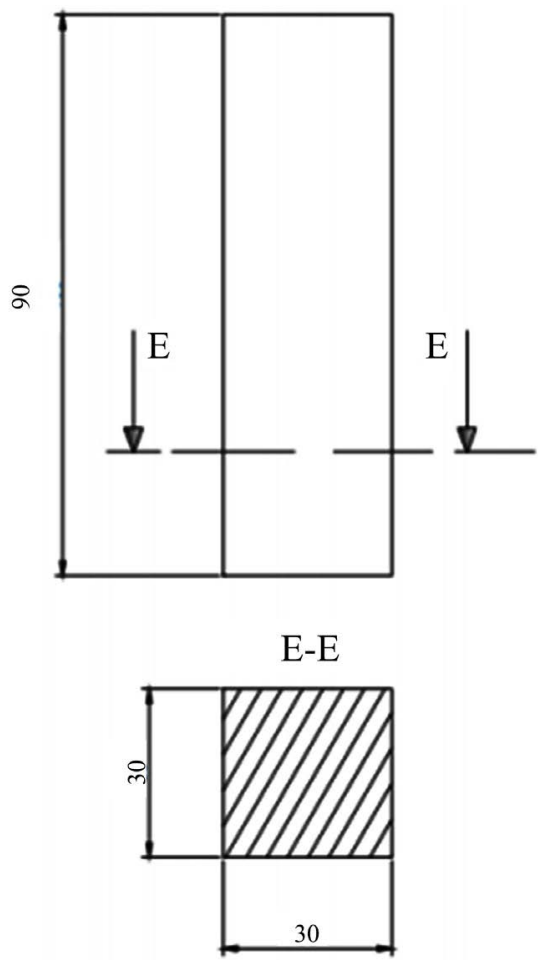

Figure 3. Compression sample of dimension $30 \times 30 \times 90 \mathrm{~mm}$.

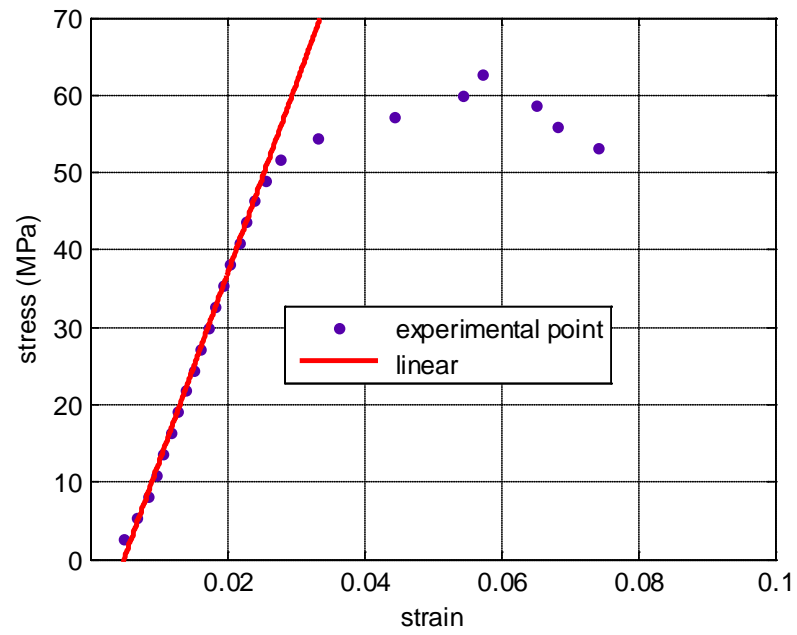



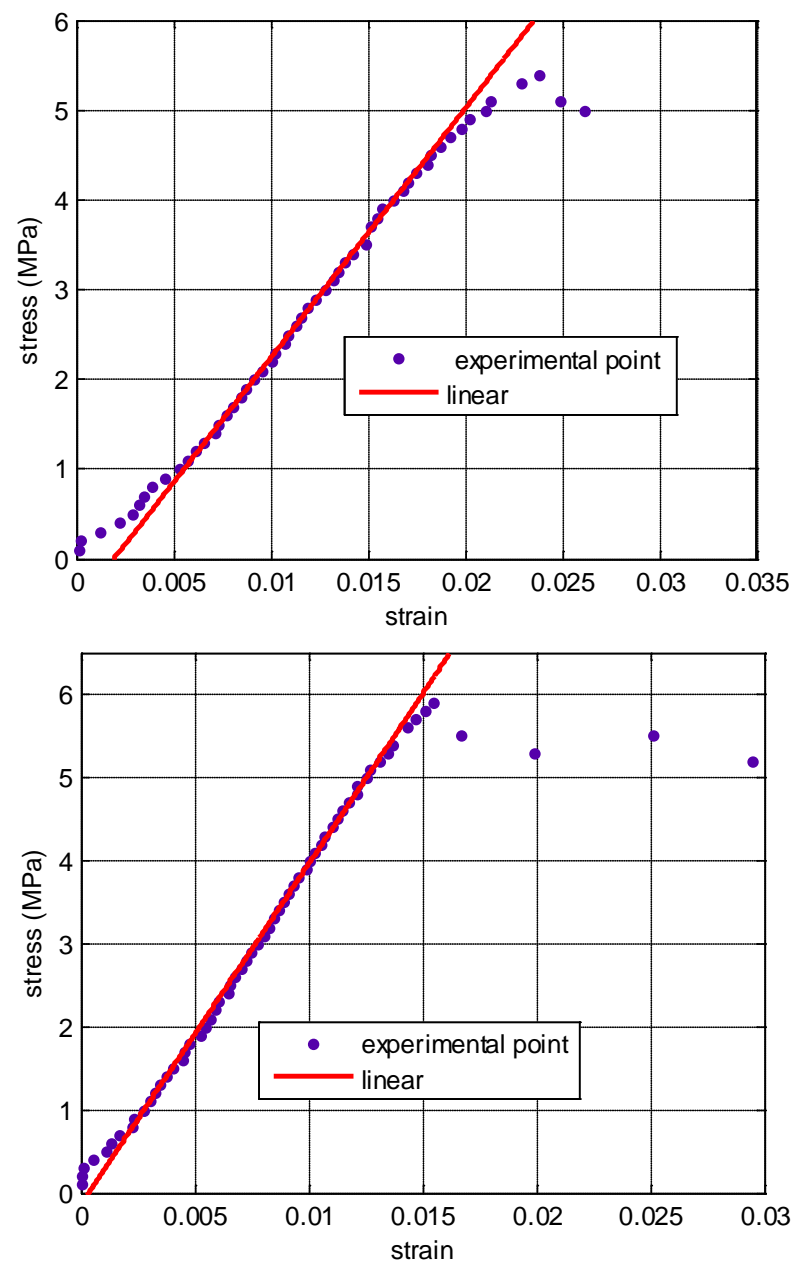

Figure 4. stress-strain curve $(\sigma=f(\varepsilon))$ the three directions of Orthotropy $L 17, T 28$ and $R 3$.

Table 1. Determination of the elastic properties of Pericopsis elata (Assamela) following the tangential direction.

\begin{tabular}{cccccccccccccc}
\hline Test-tubes & $T 28$ & $T 27$ & $T 19$ & $T 17$ & $T 15$ & $T 5$ & $T 7$ & $T 13$ & $T 25$ & $T 26$ & $T 2$ & $T 11$ & Averages \\
\hline$E_{\text {Taverage }}(\mathrm{MPa})$ & 476.35 & 502.31 & 535.03 & 504.01 & 501.18 & 475.42 & 339.45 & 716.13 & 667.52 & 360.14 & 817.3 & 769.8 & 555.39 \\
$\sigma_{\max }(\mathrm{MPa})$ & 6.3 & 5.4 & 4.5 & 5.8 & 5.4 & 6.2 & 6 & 6.4 & 5.8 & 6.4 & 6.9 & 5.15 & 5.8541 \\
$\sigma_{\text {rup }}(\mathrm{MPa})$ & 5.6 & 5 & 4.5 & 5.6 & 5 & 5.39 & 5.5 & 6.3 & 5.4 & 6.3 & 5.8 & 5.04 & 5.4525 \\
$\varepsilon_{\text {rup }}(\%)$ & 0.026 & 0.026 & 0.024 & 0.043 & 0.026 & 0.031 & 0.042 & 0.041 & 0.033 & 0.042 & 0.037 & 0.024 & 0.033 \\
Water content & & & & & & & & & & & & &
\end{tabular}

Table 2. Determination of the elastic properties of Pericopsis elata (Assamela) in radial direction.

\begin{tabular}{cccccccccccccc}
\hline Test-tubes & $R 1$ & $R 2$ & $R 3$ & $R 10$ & $R 32$ & $R 45$ & $R 28$ & $R 6$ & $R 38$ & $R 31$ & $R 23$ & $R 17$ & Averages \\
\hline$E_{\text {Raverage }}(\mathrm{MPa})$ & 766.69 & 878.69 & 983.71 & 859.38 & 813.04 & 827.03 & 899 & 938.2 & 1095 & 1478 & 847.47 & 915.89 & 953.874 \\
$\sigma_{\text {max }}(\mathrm{MPa})$ & 6.8 & 6.8 & 5.9 & 7 & 6.9 & 6.8 & 6.7 & 7.4 & 7.02 & 6.5 & 6.23 & 6.87 & 6.782 \\
$\sigma_{\text {rup }}(\mathrm{MPa})$ & 6.8 & 5.7 & 5.2 & 6.8 & 6.9 & 6.4 & 6.6 & 7 & 6.45 & 6.01 & 5.67 & 6.49 & 6.386 \\
$\varepsilon_{\text {rup }}(\%)$ & 0.029 & 0.026 & 0.029 & 0.027 & 0.039 & 0.024 & 0.023 & 0.041 & 0.037 & 0.0397 & 0.029 & 0.034 & 0.0315 \\
Water content & & & & & & & & & & & & &
\end{tabular}


Table 3. Determination of the elastic properties of Pericopsis elata (Assamela) in longitudinal direction.

\begin{tabular}{|c|c|c|c|c|c|c|c|c|c|c|c|}
\hline Test-tubes & $L 17$ & $L 23$ & $L 21$ & $L 19$ & $L 18$ & $L 12$ & $L 26$ & $L 16$ & $L 25$ & $L 22$ & Moyennes \\
\hline$E_{\text {Lmoyen }}(\mathrm{MPa})$ & 10575.63 & 11359.55 & 10872.88 & 11126.42 & 9360.41 & 7113.56 & 11135.16 & 12370.77 & 8634.77 & 11033.16 & 10358.23 \\
\hline$\sigma_{\max }(\mathrm{MPa})$ & 62.69 & 63.69 & 59.96 & 61.33 & 59.97 & 62.69 & 54.51 & 58.88 & 62.04 & 59.97 & 60.57 \\
\hline$\sigma_{r u p}(\mathrm{MPa})$ & 54.51 & 54.51 & 53.15 & 61.33 & 51.79 & 53.15 & 47.69 & 56.88 & 62.04 & 59.97 & 55.51 \\
\hline$\varepsilon_{\text {rup }}(\%)$ & 0.045 & 0.050 & 0.039 & 0.0244 & 0.062 & 0.074 & 0.044 & 0.054 & 0.038 & 0.025 & 0.046 \\
\hline$G_{L R} \approx \frac{E_{L}}{15}$ & 705.04 & 757.303 & 724.86 & 741.76 & 624.027 & 474.24 & 742.34 & 824.72 & 575.65 & 735.54 & 690.55 \\
\hline$G_{L R}=\frac{E_{L}}{17}$ & 622.09 & 668.21 & 639.58 & 654.49 & 550.61 & 418.44 & 655.01 & 727.69 & 507.93 & 649.01 & 609.31 \\
\hline$G_{L R}=\frac{E_{L}}{153}$ & 69.12 & 74.25 & 71.07 & 73.72 & 61.18 & 46.49 & 72.78 & 80.86 & 56.44 & 72.11 & 67.81 \\
\hline$\frac{E_{\text {Laverage }}}{E_{\text {Raverage }}}$ & \multicolumn{11}{|c|}{10.8591} \\
\hline$\frac{E_{\text {Laverage }}}{E_{\text {Taverage }}}$ & \multicolumn{11}{|c|}{18.6505} \\
\hline Water content & \multicolumn{11}{|c|}{$11.13 \%$} \\
\hline
\end{tabular}

\section{Tests of Loading-Unloading}

The evolution of the damage can thus be obtained in a simple way via load-discharge tests which gives direct access to the damaged moduli. It is by this method that the damaging behaviour of Pericopsis elata (Assamela) will be described. A load-unload compression test is performed on 8 test pieces. An incrementation of the stress of 8 bars is made after each cycle until the rupture of the specimen, they aim to:

- To measure the compression stress-strain curves $(\sigma=f(\varepsilon))$ of the wood material in the longitudinal direction.

- To establish a procedure for measuring the damage, by the variation of the Young modulus.

- To evaluate the decrease of the modulus of elasticity because of the damage of the material in the three directions.

- To calculate the evolution of the Young modulus and the damage during the loading phase.

- To study the reduction of the stiffness of material after each cycle, which will enable us to check the evolution of the damage in material.

The results obtained are shown in Tables 4-6. The decrease of the modulus of elasticity after each loading in the radial, tangential and longitudinal direction is due to the evolution of the damage in the material. We also note a very great improvement of the maximum stress; it is almost three times that recorded in the case of a simple compression test. The hysteresis of material increases after each cycle due to the hardening of the wood material, the stiffness of material decreases after each loading, this can be related to the damage of the wood material [27] [28]. 
Table 4. Mechanical properties of the test of compression load-discharge according to the tangential direction Mechanical properties in the tangential direction.

\begin{tabular}{cccccc}
\hline $\begin{array}{c}\text { Test-tubes } \\
\text { Young modulus }\end{array}$ & $T_{6}$ & $T_{8}$ & $T_{11}$ & $T_{2}$ & Averages \\
\hline$E_{0}(\mathrm{MPa})$ & 1067 & 938.6 & 1030 & 1004 & 1009.9 \\
$E_{1}(\mathrm{MPa})$ & 1040 & 908.9 & 876.1 & 943 & 942 \\
$E_{2}(\mathrm{MPa})$ & 963.3 & 824 & 803 & 912 & 875.575 \\
$E_{3}(\mathrm{MPa})$ & 887.7 & 640 & 769.8 & 817.3 & 778.7 \\
$\sigma_{\max }(\mathrm{MPa})$ & 14.9913 & 17.7170 & 17.7176 & 17.7127 & 17.0347 \\
\hline
\end{tabular}

Table 5. Mechanical properties of the test of compression load-discharge according to the radial direction Mechanical properties in the radial direction.

\begin{tabular}{cccccc}
\hline $\begin{array}{c}\text { Test-tubes } \\
\text { Young modulus }\end{array}$ & $R_{6}$ & $R_{31}$ & $R_{38}$ & $R_{9}$ & Averages \\
\hline$E_{0}(\mathrm{MPa})$ & 1554 & 1442 & 1374 & 1280 & 1412.5 \\
$E_{1}(\mathrm{MPa})$ & 1451 & 1119 & 1308 & 1062 & 1310 \\
$E_{2}(\mathrm{MPa})$ & 1410 & 1298 & 1255 & 1030 & 1248.25 \\
$E_{3}(\mathrm{MPa})$ & 983.2 & 1078 & 998 & 902 & 990.3 \\
$\sigma_{\max }(\mathrm{MPa})$ & 13.6284 & 16.3541 & 14.9913 & 14.6284 & 14.9005 \\
\hline
\end{tabular}

Table 6. Mechanical properties of the test of compression load-discharge according to the longitudinal direction Mechanical properties in the longitudinal direction.

\begin{tabular}{cccccc}
\hline Eprouvettes & $L_{20}$ & $L_{27}$ & $L_{13}$ & $L_{54}$ & Averages \\
\hline$E_{0}(\mathrm{MPa})$ & 12783.0802 & 11603.915 & 11087.005 & 10725.882 & 11549.97055 \\
$E_{1}(\mathrm{MPa})$ & 12134.2994 & 10811.2526 & 10751.2066 & 10530.6306 & 11031.8473 \\
$E_{2}(\mathrm{MPa})$ & 10805.4242 & 10799.5958 & 10601.5312 & 9364.9506 & 10417.7643 \\
$E_{3}(\mathrm{MPa})$ & 9249.6708 & 10076.8742 & 10045.562 & 9172.184 & 9636.07275 \\
$\sigma_{\max }(\mathrm{MPa})$ & 59.9652 & 54.5139 & 51.7881 & 58.8769 & 56.2860 \\
\hline
\end{tabular}

The reduction the modulus of elasticity can be quantified by a damage variable $D$ for each load-unload cycle by comparing the Young modulus of the damaged material to that of the undamaged material.

$$
D_{1}=1-\frac{\tilde{E}_{1}}{E}(1+v)\left[2+\tilde{v}_{12}-\frac{\tilde{E}_{1}}{\tilde{E}_{2}}\right]^{-1} \approx 1-\frac{\tilde{E}}{E}
$$

In the case of an orthotropic damage we will also have in directions 2 and 3 the expressions (8 and 9) of the damage [29]:

$$
\begin{gathered}
D_{2}=1-\frac{\tilde{E}_{2}}{E}(1+v)\left[2-\left(1-\tilde{v}_{12}\right) \frac{\tilde{E}_{2}}{\tilde{E}_{1}}\right]^{-1} \\
D_{3}=1-\frac{\tilde{E}_{3}}{E}(1+v)\left[2+\tilde{v}_{32}-\frac{\tilde{E}_{3}}{\tilde{E}_{2}}\right]
\end{gathered}
$$

where 
$v=$ poisson ratio of elastic contraction;

$E=$ modulus of elasticity;

$D$ : damage variable.

$$
\tilde{E}_{1}=\frac{\sigma_{1}}{\varepsilon_{1}^{e}}, \quad \tilde{v}_{12}=-\frac{\varepsilon_{2}^{e}}{\varepsilon_{1}^{e}} \text { and } \tilde{v}_{13}=-\frac{\varepsilon_{3}^{e}}{\varepsilon_{1}^{e}}
$$

\section{Damage during Load-Unload Tests}

The damage variable is defined, conventionally to take its values between 0 and 1 . The value 0 , which corresponds to the initial state reflects the fact that the material did not undergo any damage. That, for $D=1$, corresponds theoretically to the completely damaged state of the material [30], it is said then that the material has reached the state of ruin.

The curves in Figure 5 and Tables 7-9 give us the evolution of the damage during the compression unloading phase for the specimens in the three directions of Orthotropy. The Young modulus is calculated from the first slope of the rise during the loading. An imposed stress level of cyclic compression test is performed for 5 cycles on specimens. Then these specimens are stressed in compression until failure; the results obtained are shown in the table.

Table 7. Evolution of the damage following the tangential direction.

\begin{tabular}{ccccccccc}
\hline & \multicolumn{2}{c}{$T_{6}$} & \multicolumn{2}{c}{$T_{8}$} & $T_{11}$ & \multicolumn{2}{c}{$T_{2}$} \\
\cline { 2 - 9 } & $E(\mathrm{MPa})$ & $D$ & $E(\mathrm{MPa})$ & $D$ & $E(\mathrm{MPa})$ & $D$ & $E(\mathrm{MPa})$ & $D$ \\
\hline Cycle 1 & 1067 & 0 & 938.6 & 0 & 1030 & 0 & 1004 & 0 \\
Cycle 2 & 1040 & 0.0253 & 908.9 & 0.0316 & 876.1 & 0.1494 & 943 & 0.0608 \\
Cycle 3 & 963.3 & 0.0972 & 824 & 0.122 & 803 & 0.2204 & 912 & 0.0916 \\
Cycle 4 & 887.7 & 0.168 & 640 & 0.3181 & 769.8 & 0.2526 & 817.3 & 0.1859 \\
\hline
\end{tabular}

Table 8. Evolution of the damage in the radial direction.

\begin{tabular}{ccccccccc}
\hline & \multicolumn{2}{c}{$R_{6}$} & \multicolumn{2}{c}{$R_{31}$} & \multicolumn{2}{c}{$R_{38}$} & \multicolumn{2}{c}{$R_{9}$} \\
\cline { 2 - 9 } & $E(\mathrm{MPa})$ & $D$ & $E(\mathrm{MPa})$ & $D$ & $E(\mathrm{MPa})$ & $D$ & $E(\mathrm{MPa})$ & $D$ \\
\hline Cycle 1 & 1554 & 0 & 1442 & 0 & 1374 & 0 & 1280 & 0 \\
Cycle 2 & 1451 & 0.0663 & 1298 & 0.0998 & 1308 & 0.0480 & 1062 & 0.1703 \\
Cycle 3 & 1410 & 0.0927 & 1119 & 0.2239 & 1255 & 0.0866 & 1030 & 0.1953 \\
Cycle 4 & 983.2 & 0.3673 & 1078 & 0.2524 & 998 & 0.2736 & 902 & 0.2953 \\
\hline
\end{tabular}

Table 9. Evolution of the damage in the longitudinal direction.

\begin{tabular}{cccccccccc}
\hline & \multicolumn{2}{c}{$L_{27}$} & \multicolumn{2}{c}{$L_{20}$} & \multicolumn{2}{c}{$L_{13}$} & \multicolumn{2}{c}{$L_{54}$} \\
\cline { 2 - 9 } & $E(\mathrm{MPa})$ & $D$ & $E(\mathrm{MPa})$ & $D$ & $E(\mathrm{MPa})$ & $D$ & $E(\mathrm{MPa})$ & $D$ \\
\hline Cycle 1 & 12603.915 & 0 & 13783.0802 & 0 & 12603.915 & 0 & 12679.19805 & 0 \\
Cycle 2 & 11811.2526 & 0.06289 & 13134.2994 & 0.047 & 11811.2526 & 0.0629 & 12071.8588 & 0.0479 \\
Cycle 3 & 11799.5958 & 0.06382 & 11805.4242 & 0.1435 & 11799.5958 & 0.0638 & 11442.3916 & 0.0975 \\
Cycle 4 & 11076.8742 & 0.1212 & 9249.6708 & 0.3289 & 11068.512 & 0.1218 & 10391.81025 & 0.1804 \\
\hline
\end{tabular}



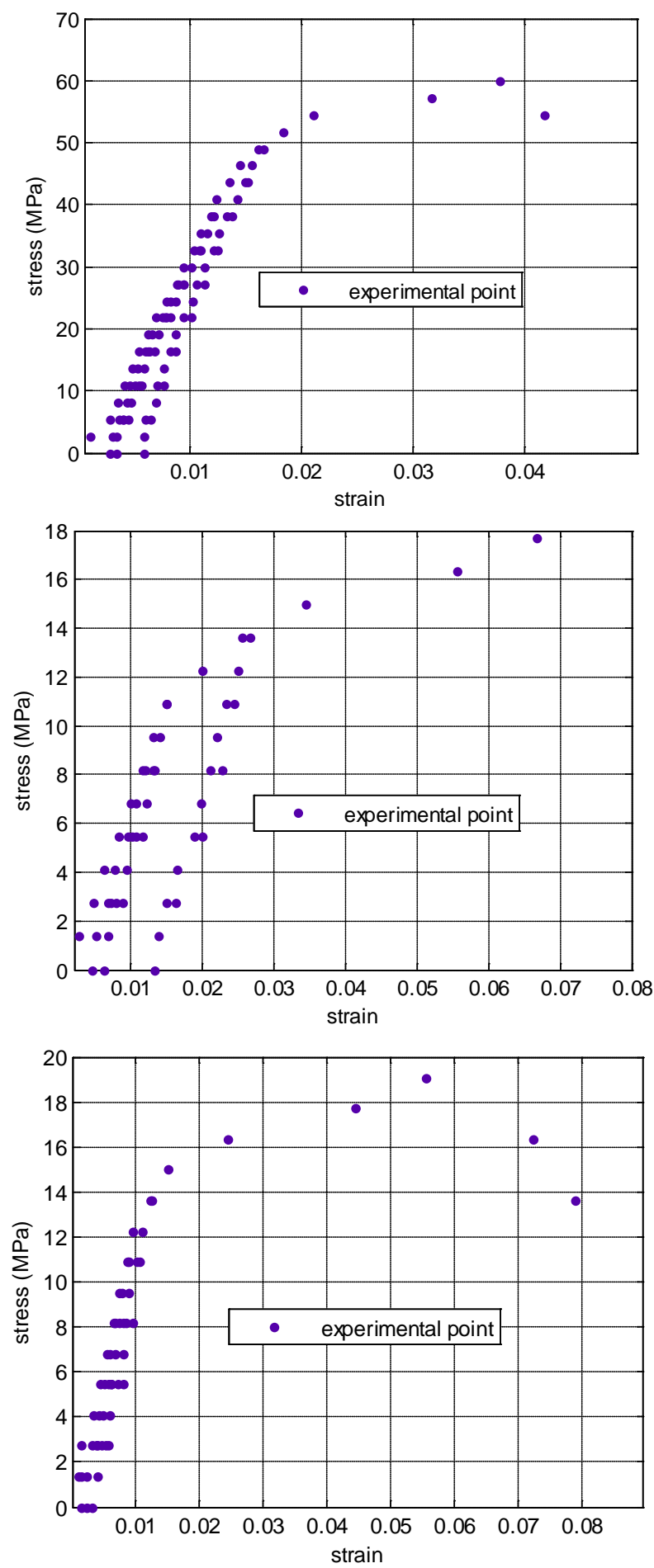

Figure 5. Load-unload tests at imposed stress level in the three directions of orthotropy $\left(L_{13}, T_{12}\right.$ and $\left.R_{6}\right)$.

The cycles of loading-unloading at imposed stress level have a non-linearity which primarily finds its origin in the following sources:

- Residual deformations that may result from a release of stresses,

- It progressive and irreversible degradation of the mechanical properties in- 
duced by the development of microcracks in the material.

When the imposed stress is greater than a certain critical value, then compliance no longer has a relaxed limit value and the test leads to ruin if the load is maintained. The ruin of the material is observed for a critical value of the damage $D_{C}$ much lower than the conventional value 1 , in all cases. This reflects the fact that the process of damage is not a slow and progressive process. Moreover, a sudden rupture is observed experimentally, which corresponds to a value of critical damage $D_{C}$ (Tables 7-9).

\section{Conclusion}

This work was devoted to the determination of the mechanical characteristics according to the three directions of Orthotropy and also to the determination of the damage in three directions by method of variation of the Young modulus (healthy and damaged Young modulus). After carrying out the compression tests on the different specimens, the results obtained showed the influence of the orientation of the fibers (Longitudinal, Radial, Tangential) on the mechanical response of the properties. We noted that wood is a very complex material, heterogeneous and orthotropic; its mechanical properties strongly vary according to the direction of request of the gasoline and the scale considered. We noticed that the wood is a very complex material, heterogeneous and orthotropic; its mechanical properties vary greatly depending on the direction of loading of the species and the scale considered. Load-unload compression tests at the imposed stress level have shown the evolution of the damage in the nonlinear phase of the stress-strain curve; we have found that the value of the critical damage $D_{C}$ is less than the theoretical value in all cases. In the future, it will be interesting to simulate the theoretical damage and compare its behavior with that of the critical damage.

\section{Conflicts of Interest}

The authors declare no conflicts of interest regarding the publication of this paper.

\section{References}

[1] Zhang, L. and Yu, W.B. (2017) Constitutive Modeling of Damageable Brittle and Quasi-Brittle Materials. International Journal of Solids and Structures, 117, 80-90. https://doi.org/10.1016/j.ijsolstr.2017.04.002

[2] Wu, J.Y., Li, J. and Faria, R. (2006) An Energy Release Rate-Based Plastic-Damage Model for Concrete. International Journal of Solids and Structure, 43, 583-612. https://doi.org/10.1016/j.ijsolstr.2005.05.038

[3] Taqieddin, Z., Voyiadjis, G. and Almasri, A. (2011) Formulation and Verification of Concrete Model with Strong Coupling between Isotropic Damage and Elastoplasticity and Comparison to a Weak Coupling Model. Journal of Engineering Mechanics, 138, 530-541. https://doi.org/10.1061/(ASCE)EM.1943-7889.0000344

[4] Abu Al-Rub, R. and Kim, S. (2010) Computational Applications of a Coupled Plas- 
ticity-Damage Constitutive Model for Simulating Plain Concrete Fracture. Engineering Fracture Mechanics, 77, 1577-1603.

https://doi.org/10.1016/j.engfracmech.2010.04.007

[5] Xavier, J., De Jesus, A. and Pinto, J. (2012) Stereovision Measurements on Evaluating the Modulus of Elasticity of Wood by Compression Tests Parallel to the Grain. Construction and Building Materials, 26, 207-215. https://doi.org/10.1016/j.conbuildmat.2011.06.012

[6] Ciecekli, U., Voyiadjis, G. and Abu Al-Rub, R. (2007) A Plasticity and Anisotropic Damage Model for Plain Concrete. International Journal of Plasticity, 23, 1874-1900. https://doi.org/10.1016/j.ijplas.2007.03.006

[7] Rabotnov, Y.N. (1969) Creep Problem in Structural Members. Elsevier, North Holland.

[8] Kachanov, L.M. (1958) Time of Rupture Process under Creep Conditions. OtdelenieTekhnicheskichNauk, 8, 26-31.

[9] Murakami, S. and Ohno, N. (1978) A Constitutive Equation of Creep Damage in Polycrystalline Metals. IUTAM Colloquium Euromech 111, Marienbad.

[10] Aira, J.L., Arriage, F. and Iniguez-Gonzalez, G. (2014) Determination of the Elastic Constants of Scots Pine (Pinus sylvestris L.) Wood by Means of Compression Tests. Biosystems Engineering, 126, 12-22.

[11] Chaboche, J.L. (1978) Description thermodynamique et phénoménologique de la viscoplasticité cyclique avec endommagement. Office national d'études et de recherches aérospatiales, Palaiseau.

[12] Lemaitre, J., Desmorat, R. and Sauzay, M. (2000) Anisotropic Damage Law of Evolution. European Journal of Mechanics and Solids, 19, 197-208. https://doi.org/10.1016/S0997-7538(00)00161-3

[13] Desmorat, R. and Otin, S. (2007) Cross-Identification Isotropic/Anisotropic Damage and Application to Anisothermal Structural Failure. Engineering Fracture Mechanics, 75, 3446-3463.

[14] Ghousson, M.A. (2014) The Cyclic Loading of Concrete in a Specific Stress Range. Jordan Journal of Civil Engineering, 8, 271-281.

[15] Park, R., Kent, D.C. and Sampson, R.A. (1972) Reinfored Concrete Member with Cyclic Loading. Journal of the Structural Division, 98, 1341-2360.

[16] Ristic, D. (1988) Nonlinear Behavior and Stress-Strain Based Modeling of Reinforced Concrete Structure under Earthquake Induced Bending and Varying Axial Loads. School of Engineering, Kyoto University, Kyoto.

[17] Sima, J.F. Roca, P. and Molins, C. (2007) Cyclic Constitutive Model for Concrete. Engineering Structures, 30, 695-706.

[18] Bangash, M.Y. (1964) Manuelof Numerical Methods in Concrete. Thomas Telford, London.

[19] Pellerin, R.F. and Ross, R.J. (2002) Nondestructive Evaluation of Wood. Forest Products Society, Madison.

[20] Fahim, S. and abd Gross, J.L. (1999) Structural Performance of Woodframe Housing: State-of-the-Art and Research Needs, Seisme Testing. Analyse and Design of Woodframe Construction Proceedings, Richmond, 121-123.

[21] Breyer, D.E. and Ank, J.A. (1980) Design of Wood Structures. McGraw-Hill, New York.

[22] Guitard, D. (1987) Mécanique du matériau bois et composite. éd. Cépaudes.

[23] José, R.A., Francisco, A. and Guillermo, G. (2014) Determination of the Elastic 
Constants of Scots Pine (Pinus sylvestris L.) Wood by Means of Compression Tests. Biosystems Engineering, 126, 12-22.

https://doi.org/10.1016/j.biosystemseng.2014.07.008

[24] Arguelles-Alvarez, R., Arriaga, F. and Martinez, J. (2000) Wood Structure. Design and Calculation. 2nd Edition, Association of the Technical Investigation of the Industries of the Wood and Cork (AITIM).

[25] NF B 51-004. Bois (1985) Détermination de l'humidité. AFNOR, Paris.

[26] Kollmann, F. and Côté, W. (1968) Principles of Wood Science and Technology. Volume 1, Solid Wood. Springer-Verlag, New York. https://doi.org/10.1007/978-3-642-87928-9

[27] Ayssedat, Y.E. (1997) Comportement et endommagement du composite tissé carbone/PMR15 soumis à des chargements mécaniques et thermiques. Thèse de doctorat, École Nationale Supérieure des Mines de Paris.

[28] Barret, C. (1999) Endommagement induit par des fissures elliptiques d'orientations multiples dans des matériaux composites à matrice céramique. Thèse de doctorat, Université de Bordeaux I.

[29] Lemaitre, J. and Desmorat, R. (2005) Engineering Damage Mechanics Ductile, Creep, Fatigue and Brittle Failures. Springer-Verlag, Berlin, Heidelberg.

[30] Lemaitre, J. (1981) Tensorial Nature of Damage Measuring Internal Variables. 